BNL --46745

DE92 005006

\title{
LOCATING OF LEAKS IN WATER-COOLED GENERATOR STATOR BARS USING PERFLUOROCARBON TRACERS
}

W. M. Loss and R. N. Dietz

Tracer Technology Center

Brookhaven National Laboratory

Upton, NY 11973

September 1991

Prepared for

$\Lambda$ ir. Peter Nugent

Consolidated Edison Co. of New York, Inc.

New York, NY 10003

UNDER CONTRACT NO. DE-AC02-76CH00N16 WITH THE UNITED STATES DEPARTMENT OF ENERGY. 
Table of Contents

\section{Abstract}

1. Introduction

2. Experimental Set-up

3. Discussion and Results of Perfluorocarbon Tracer Tests

3.1 Testing of 3 Individual Bars

3.2 Generator In-Situ Testing

4. Recommendations

5. Conclusions

6. References

\section{APPENDIX}

A.1. General Leak Search Protocol

2.1 Failed Bar Testing

2.2 In-Situ Testing

A2. Theoretical Considerations

A3. Perfluorocarbon Tracer Instruments

A4. Perfluorocarbon Tracer Technology 


\begin{abstract}
Water cooled stator bars in power plant generators often fail during the maintenance cycle due to water leakage. After the hydrogen pressure in the generator shell has been released water can leak through cracks in the copper and through the insulation. Leaking bars, but not the leaks themselves, are detected with so-called "hi-pot" (high potential) tests where direst electrical current is applied to the stator bar windings.
\end{abstract}

A study was initiated by ConEd and Brookhaven's Tracer Technology Center to explore the cause of these leakage problems and to determine if the failures originate in the manufacturing process or are created in service by phase related torque stresses.

To this purpose bars that had failed the hi-pot test were investigated first with the insulation in place and then stripped to the bare copper. The bars were pressurized with gases containing perfluorocarbon tracers and the magnitude and location of the leaks was detected by using tracer technology principles and instruments such as the "double source" method and the Dual Trap Analyzer. In the second part of the project the windings within a generator were tested in-situ for leaks during an outage using tracer principles.

Leakage rates for individual bars were about $0.1 \mathrm{ml} / \mathrm{min}$ at $15 \mathrm{psi}$, the assumed operating pressure. Water can travel several feet underneath the insulation before finding its way to the outside. Cracks and pinholes on the bare copper apparently develop within a few inches from the water box. The bars are now undergoing a metallurgical investigation to determine the cause of the leaks.

Leakage of the entire, in-situ stator bar assembly was found to be around 5 $\mathrm{ml} / \mathrm{min}$. Interesting!y, both rates, those for failed bars as well as the in-situ bars were substantialiy lower than a currently existing guide line allowing for $50 \mathrm{ml} / \mathrm{min}\left(2-3 \mathrm{ft}^{3} / \mathrm{d} \cdot \mathrm{y}\right)$ of vent flow rate from the cooling water iank.

Recommendations are given suggesting the shut down of stator bar cooling water before hydrogen bleeding during outages and a revision of the current vent flow rate. The new standard should establish a reasonable leak rate for the stator bar windings proper and exclude leakage of pump seals and connections. Testing during the maintenance cycle in generators should include routine tracer leak detection following the hi-pot test. 


\section{Introduction}

The goal of this study is the exploration of the causes of fluid leakage from water cooled stator bars. It is not known if these failures originate in the manufacturing process by bending or brazing or are created by phase related torque stresses in service. In any event, tiny cracks develop in the copper strands allowing the cooling water to escape during the maintenance cycle after the hydrogen pressure is released. After start-up, the ground path created by the water could induce catastrophic failure of the generator unit.

Traditionally, leaking stator bars were detected by applying direct electrical current to the windings ("hi-pot" test). The failing bars were removed from the generator and replaced by new ones. Only recently was it attempted to find the actual leak location on the copper by subjecting the bars to hydraulic pressurization. These tests failed because water evaporation rates excesded the corresponding leak rates.

The Tracer Technology Center (TTC) at Brookhaven National Laboratory (BNL) suggested to ConEdison the application of perfluorocarbon tracer (PFT) gases for improved leak detection. Current PFT technology, through various sampling and analysis approaches, permits the measurement down to background concentrations of $10^{-15}$ to $10^{-16}$ liters of tracer per liter carrier gas.

In 1989 and 1990 Brookhaven demonstrated the ability of the perfluorocarbon tracer technology (PFT) to locate and quantify leaks in generator stator bars. The first "Failed Bar Testing " (Loss, et al., 1989) took place at Brookhaven with stator bar $\# 31$ that had been removed from the Ravenswood Generating Station. That bar which still carried its fiberglass insulation displayed a leak near one of the water boxes. The first "In-Situ Testing" of a whole generator was undertaken at Union Electric's Labadie plant in St. Louis, Missouri (Loss and Dietz, 1990).

Based on the positive identification of a leak on stator bar \#31 ConEd approached the Tracer Technology Center again in September of 1990. Two bars, namely bar \# 53 and \# 21 from Unit 1 and Unit 2, respectively, at the Ravenswood Station had failed the hi-pot test due to water leaks. It was planned to subject these bars to the "Failed Bar Testing Protocol" but now the goal of the leak search was twofold: first to find the leak(s) on the surface of the insulation and second to locate the actual points of egress on the bare copper itself.

The reason for this approach was the assumption that water travels below the surface of the insulation for quite some distance and then emerges 
through cracks in the insulation at places far removed from the original, actual leak location on the copper. It was hoped that besides finding the leaks themselves some insight might be gained as to the distance and direction of this water movement within the insulation.

Although not part of this report, the total ConEd-Brookhaven stator bar joint project also includes an assessment of the metallurgical conditions at the points(s) of failure of each of the bars. The metallurgical studies are conducted separately by the Manhattan based company Lucius Pitkin, Inc., which will formulate their program based upon the conclusions of the TTC Study.

The findings of this study are sumrnarized and discussed in the chapter 'Discussions'. The general leak search protocol is thoroughly reviewed in Appendix A1. The theoretical background for all the formulas used is provided in Appendix A2. Appendix A3 depicts the PFT sampling instruments. A general description of the tracer technology, including potential utility-related applications is given in Appendix A4.

\section{Experimental Set-up}

\subsection{Failed Bar Testing}

The test protocol for bars that failed the hi-pot test is explained in detail in Appendix A1. Essentially, the protocol consisted of two phases. During the first phase the bar with either the fiberglass or mica insulation still in place was subjected to a series of four tests:

1. Pneumatic pressure decay tests to determine the total leak rate.

2. "Double source" tracer tests to corroburate decay test.

3. Approximate leak locating using tracer and bar enclosure.

4. Leak pinpointing and leak verification in water bath.

During the second phase the leaking part of the stator bar, stripped of all insulation, was submerged in a water bath to locate the actual points of egress on the copper. Hence, phase 2 consisted of only 1 step:

5. Leak pinpointing in water bath. 
The experimental set-up is shown in Figure 1. After extensive purging with helium to remove all remaining water the bars were pressurized to 200 psi with helium and the pressure decay was observed over time, yielding the overall leak rate (see Appendix A2 for theory).

That leak rate was then corroborated by the "double source" method. The bar was pressurized to 200 psi with nitrogen containing the tracer PMCP (perfluoro-methylcyclopentane). A second tracer source, PMCH (perfluoromethylcyclohexane), enclosed in a small cylindrical (cigarette shaped) container with a known emission rate was also deployed in the room. The concentration ratio (at steady state) of the two tracers in the room allowed the calculation of the source or leak rate of the first tracer from the bar (see Appendix A2 for theory).

The approximate leak location was found by enclosing the bar with a one foot plastic bag. A hose was inserted into the bag and connected to the Dual Trap Analyzer (see Appendix A3 for description of instrument). High readings of that instrument indicated a leaking section.

The exact location of the leak was determined by submerging this section in a water bath. The magnitude of the leak was found by capturing the rising bubbles with an inverted calibrated glass cylinder initially filled with water. The bubbles displaced the water at a rate identical to the leak rate.

\subsection{Generator In-Situ Testing}

The test protocol for the in-situ testing is explained in detail in Appendix A1. Here too, the protocol consisted of two phases. During the first phase the generator shell was enclosed with plastic sheets and the leaking tracer was allowed to build up to a steady state concentration within the enclosure. Phase 1 encompassed the following tests:

1. Pneumatic pressure decay tests to determine the total leak rate.

2. "Double source" tracer tests to corroborate decay test.

3. Approximate leak locating using tracer and CATS tubes.

4. Determination of concentration build-up versus time. 


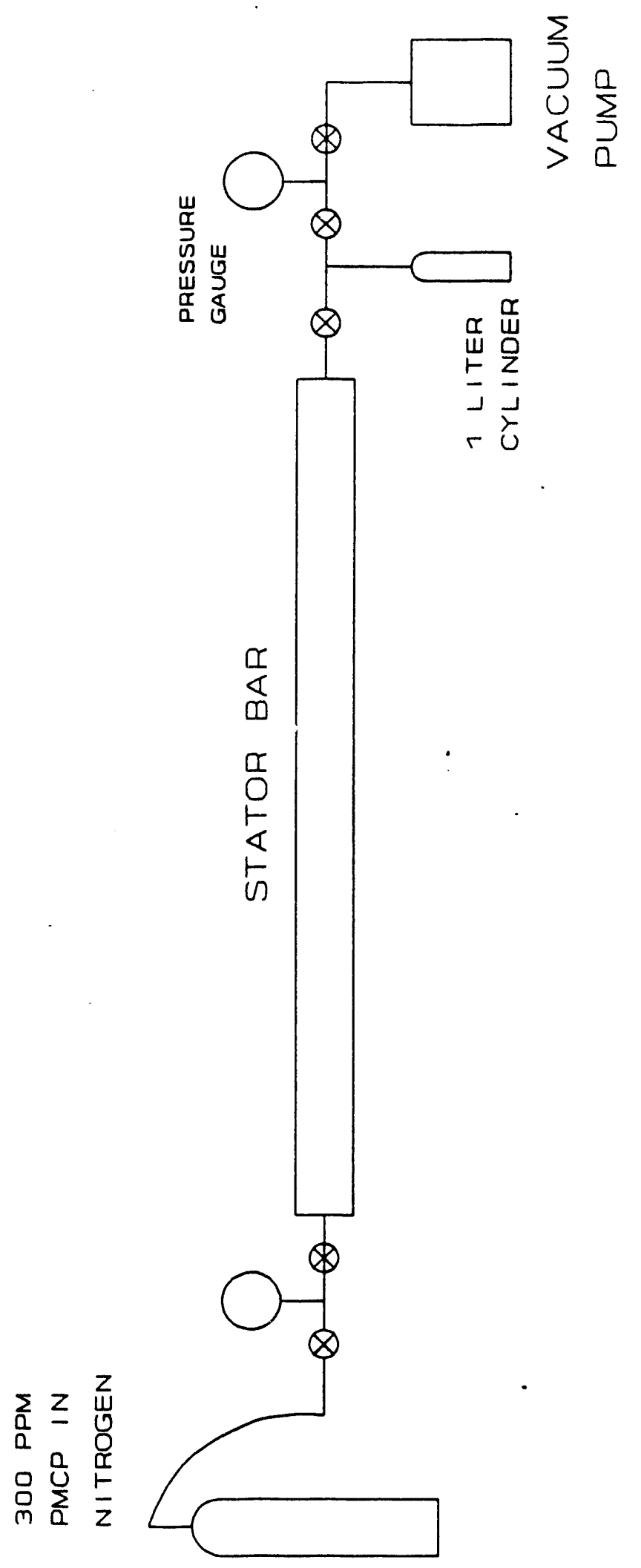

Figure 1: Experimental Set-Up, Failed Bar Testing 
Phase two consisted of leak pinpointing and quantification of the individual leak rates. During this phase the plastic sheets were removed from the generator shell and two tests were performed:

5. Leak pinpointing with halogen leak detectcr.

6. Quantification of individual leak rates with DTA.

The experimental set-up is shown in Figure 2. After purging with helium, the overall leak rate was determined by pressure decay. The "double source" method was then applied to corroborate the overall leak rate. The generator shell was closed off with plastic sheets, the windings were pressurized to 5 psi with nitrogen containing $300 \mathrm{ppm}$ of the tracer PMCP and CATS tubes were attached to each third bar (see Appendix A3 for description of capillary adsorption tube samplers or CATS tubes).

The second source necessary for this experiment was provided by installing a cylinder with $1 \mathrm{ppm}$ of $\mathrm{PMCH}$ in nitrogen within the generator enclosure. That cylinder released the $\mathrm{PMCH}$ with a known flow rate. As before, the concentration ratio of the two tracers, namely PMCP from the stator bars and PMCH from the cylinder, allowed the calculation of the PMCP leak rate. The two concentrations were found by analysis of the CATS tubes, which were kept in the enclosi \& for about one day (see Figure 2).

Concentration peaks foind in the CATS tubes also pointed to "hot spots" thus enabling approximate leak locating.

Concentration build-up versus time was measured with the BATS programmable sampler (see Appendix A3 for description of this instrument). With the BATS it was possible to find the break-through time of the tracer from the stator windings into the generator enclosure. Also, it was learned at which of the two opposite ends of the generator the larger leaks occurred ince faster build-up represents a larger leak.

Leak pinpointing was achieved with a hand held halogen leak detector which had settings for small, medium and large leaks (small leaks $<210^{-3}$ $\mathrm{ml} / \mathrm{min}$, large leaks $<0.05 \mathrm{ml} / \mathrm{min}$ ). The exact magnitude of these leaks was measured with Dual Trap Analyzer. 


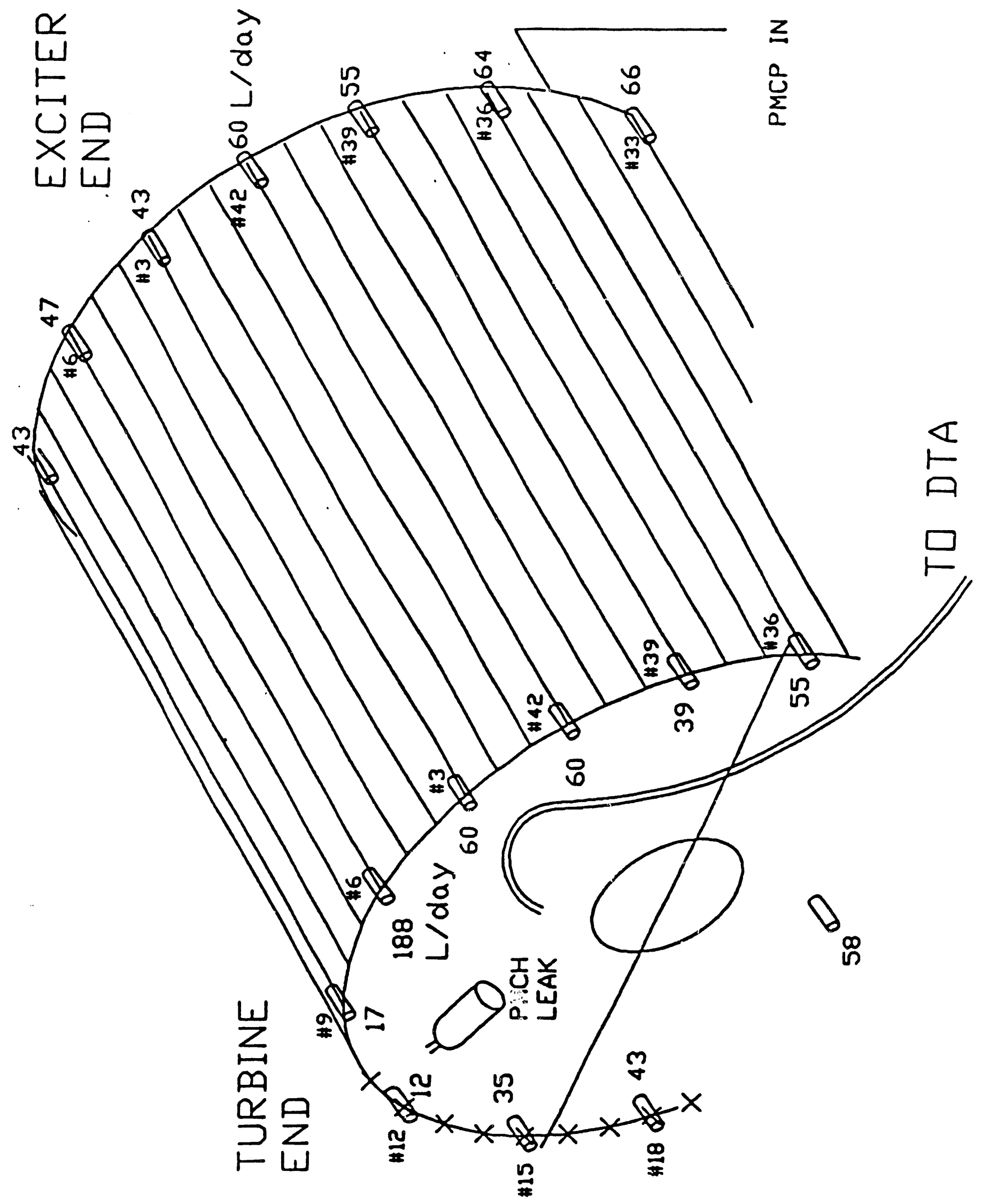

Figure 2: Experimental Set-up, In-Situ Testing 


\section{Discussion and Results of Perfluorocarbon Tests}

\subsection{Testing of 3 Individual Bars}

Table 1 outlines the results of the "Failed Bar Testing".

Following the pertinent steps outlined in Appendix A1 it became apparent that most leaks occur a few inches away from the water box.

The total leak rate (normalized to $15 \mathrm{psi}$ of pressure) found for bar \#31 was $0.11 \mathrm{ml}$ of nitrogen gas per min using pressure decay and $0.1 \mathrm{ml} / \mathrm{min}$ applying an inverted calibrated cylinder in a water bath (the "double source" method was not used in this case). The bar enclosure test showed a large peak at one end close to the water box. Pinpointing in a water bath revealed the location on the surface. With the insulation, the distance from the water box to the point of egress was 1.5 inches, without insulation it was 1.1 inches.

The leak rates for bar \#53 were of comparable magnitude. The rate of $0.09 \mathrm{ml} / \mathrm{min}$ was obtained with the pressure decay meihod and the PFT "double source" method yielded a somewhat lower result of $0.085 \mathrm{ml} / \mathrm{min}$. Leak locations with and without insulation were around 1 inch from the water box.

Bar \#21 afforded the most interesting observations. During Phase 1 testing with the insulation in place neither pressure decay nor PFT "double source" tracing produced any noticeable leaks. Nevertheless, it was decided to try to find leaks with the bar enclosure method. A plastic bag of 1 foot length was wrapped around the bar and the air from this bag was introduced to the Dual Trap Analyzer. Section after section of 1 foot length was covered with the bag and analyzed for PFT content. Despite meticulous efforts lasting for more than one week, no PFT could be found. It was therefore concluded that bar $\$ 21$ did not have any measurable leaks with the insulation in place.

It was noticed, though, that the insulation appeared spongy on a two foot segment on the straight center portion of the bar immediately adjacent to the bend. This raised questions as to the existence of a leak that might have been veiled by the air and water tightness of the insulation.

After stripping, bar \#21 was returned to Brookhaven with the major part of the insulation removed; only a thin layer of mica had been left. After hook-up to the test arrangement as depicted in Figure 1 the tagging procedure started again by opening the PMCP-in-nitrogen source cylinder. Surprisingly, 
Table 1

Results of Failed Bar Testing

\begin{tabular}{|c|c|c|c|c|c|c|c|}
\hline \multirow[t]{3}{*}{ bar } & \multicolumn{2}{|c|}{$\begin{array}{l}\text { Leak } \\
\text { Location }\end{array}$} & \multicolumn{2}{|c|}{$\begin{array}{l}\text { Distance from } \\
\text { Water Box, inches }\end{array}$} & \multirow{2}{*}{\multicolumn{2}{|c|}{$\begin{array}{c}\text { Leak Rate } \\
\mathrm{ml} / \mathrm{min} \\
\text { (at } 15 \mathrm{psi} \text { ) }\end{array}$}} & \multirow{3}{*}{$\begin{array}{l}\text { Tracer } \\
\text { used }\end{array}$} \\
\hline & \multirow{2}{*}{$\begin{array}{l}\text { Set of } \\
\text { Strands }\end{array}$} & \multirow{2}{*}{$\begin{array}{l}\text { Strand } \\
\text { Number }\end{array}$} & \multirow[b]{2}{*}{ with Ins. } & \multirow[b]{2}{*}{ w/o Ins. } & & & \\
\hline & & & & & with Ins. & w/o Ins. & \\
\hline 31 & $\begin{array}{l}\text { outer set } \\
\text { outer } \\
\text { surface }\end{array}$ & $2 \& 3$ & 1.5 & 1.1 & 0.1 & 0.1 & $\begin{array}{l}3 \text { ppm PMCP } \\
\text { in hydrogen }\end{array}$ \\
\hline \multirow[t]{2}{*}{53} & $\begin{array}{l}\text { outer set } \\
\text { outer } \\
\text { surface }\end{array}$ & $4 \& 5$ & 1 & 0.8 & 0.09 & 0.09 & $\begin{array}{l}3 \mathrm{ppm} \text { PMCP } \\
\text { in nitrogen }\end{array}$ \\
\hline & $\begin{array}{l}\text { outer set } \\
\text { inner } \\
\text { surface }\end{array}$ & $1 \& 2$ & $?$ & 1.3 & & & \\
\hline 21 & $\begin{array}{r}\text { outer set } \\
\text { outer } \\
\text { surface }\end{array}$ & & $\begin{array}{l}\text { several } \\
\text { feet to } \\
\text { puffy } \\
\text { section }\end{array}$ & $\begin{array}{l}3.0 \\
\text { (on mica } \\
\text { see Figure } 3 \text { ) }\end{array}$ & 0 & very large & $\begin{array}{l}300 \text { ppm PMC } \\
\text { in aitrogen }\end{array}$ \\
\hline
\end{tabular}


the attempted pressurization immediately failed due to two long but thin fractures that were clearly visible on the mica. The cracks were located on the outer set of strands, about 3 inches away from the water box as shown on Figure 3. Figure 4 is a close-up of these openings illustrating their shape and position. Because these leaks were so large that they allowed the nitrogen to flow out freely no further pinpointing procedure was necessary.

It was assumed that during operation water had leaked out through the mica, traveled along the $45^{\circ}$ section of the bar to the straight part where it collected between the mica and the last layer of insulation. That water pocket was the reason for the puffy appearance noticed earlier and for the very low meter reading during the hi-pot test (actually, the bar had not failed the test but had only exhibited very low resistance values). Evidently, the strength of the insulation had prevented the nitrogen gas from penetrating out to the environment during the first round of leak locating.

\subsection{Generator In-Situ Testing}

In 1989 generator \#4 at Union Electric's Labadie power plant near St. Louis, Missouri, produced alarming cooling vent flow rates of up to 170 $\mathrm{ft}^{3} /$ day. GE specifications for hydrogen "in-leakage" allow $2-3 \mathrm{ft}^{3} /$ day $(50$ $\mathrm{ml} / \mathrm{min}$ ) at average operating pressure differentials. At Labadie water inlet pressures were reported to be $45 \mathrm{psi}$ and hydrogen pressures were maintained at $60 \mathrm{psi}$ amounting to a pressure differential of $15 \mathrm{psi}$ (The respective values at the ConEd Ravenswood plant are 32 psi for water and 45 psi for hydrogen with a pressure difference of $13 \mathrm{psi}$ ).

Pressure decay testing undertaken by plant personnel during an outage revealed a normalized "out-leakage" rate of helium and $\mathrm{SF}_{6}$ of about 0.75 $\mathrm{ft}^{3} /$ day or $15 \mathrm{ml} / \mathrm{min}$ at $15 \mathrm{psi}$, well within specifications. It had to be assumed that a large part of the large cooling vent flow originated from leaking pump seals and pipe connections.

Nevertheless, verification of the leak rates seemed justifiable and the help of Brookhavens TTC was requested. TTC staff first applied the "double source" method to corroborate the leak rate found by pressure decay. The bars were tagged - that is pressurized - to 5 psi with nitrogen containing 300 ppm of the tracer PMCP. A PMCH cylinder was deployed as the second source within the generator shell. It would have been preferable to put this cylinder closer to the center of the generator, but this was not possible because the rotor had not been removed. CATS rubes were deployed on every third bar within the shell at either end to measure the average concentration of the 


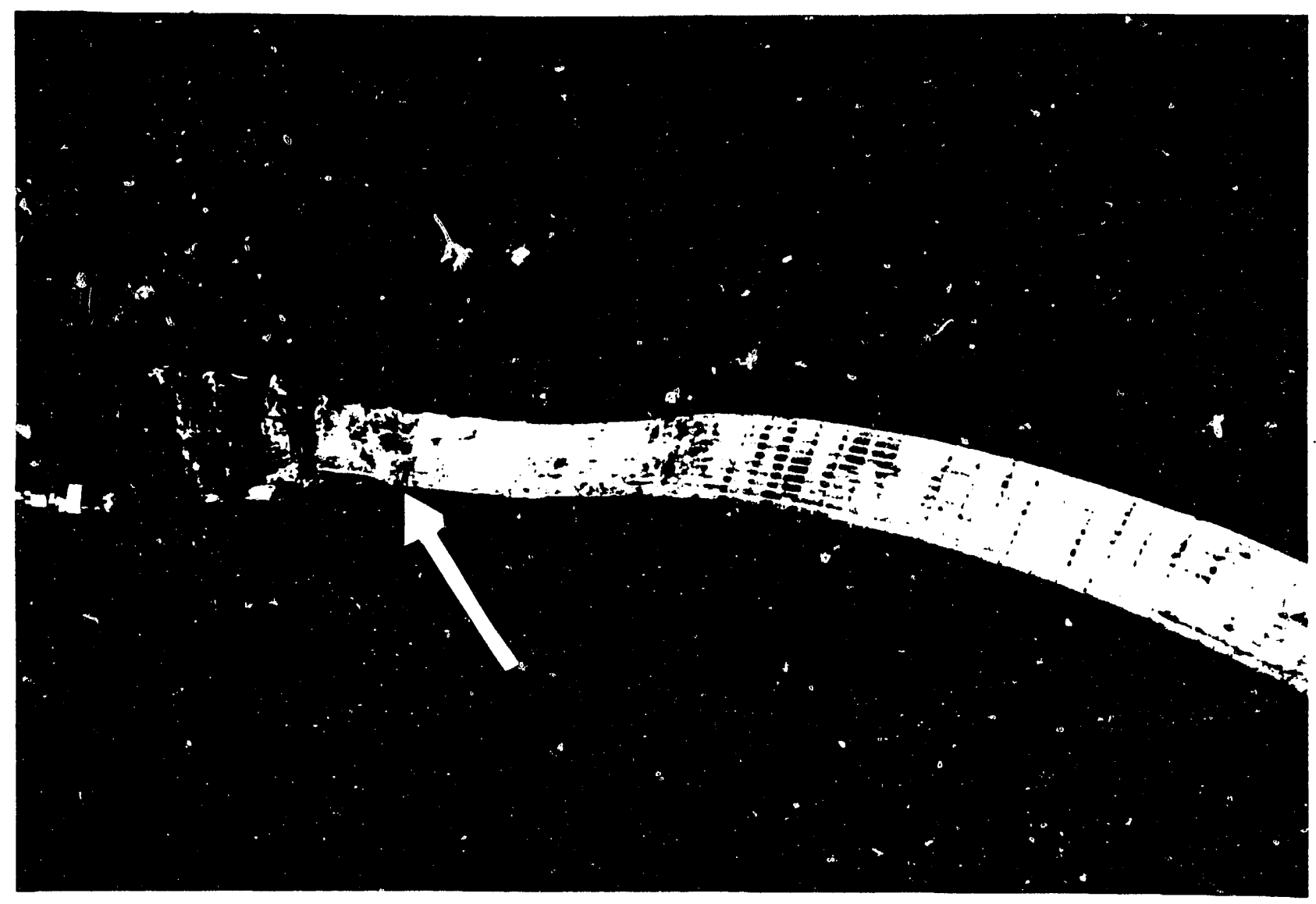

Figure 3: Stator Bar \#21, Leaking End Section 


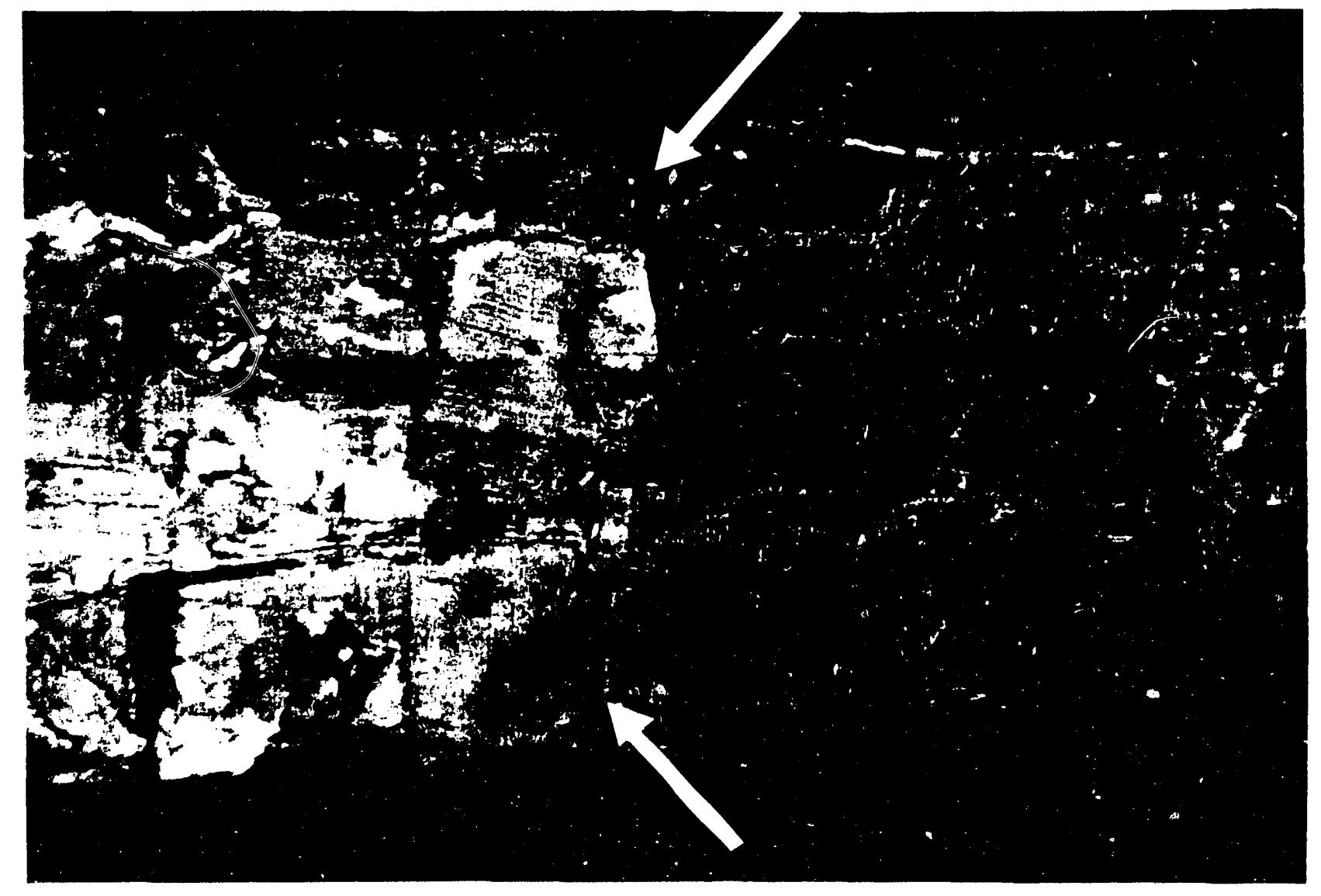

Figure 4: Stator Bar \#21, Close-Up of Leaks 
two tracers. The normalized leak rate determined with the "double source" method amounted to about $0.25 \mathrm{ft}^{3} /$ day or $5 \mathrm{ml} / \mathrm{min}$ at the average operating pressure of 15 psi. This was only one third of the leak rate found by pressure decay $(15 \mathrm{ml} / \mathrm{min})$. The difference between pressure decay and "double source" method was thought to stem from leaks in fittings and pipes leading to and from the generator windings.

Approximate leak locating through analysis of the CATS tubes which had been attached to every third bar on the upper, accessible half of the generator revealed high concentrations or "hot spots" around bar \#6 at the turbine end (see Figure 2).

With the BATS programmable sampler, it was learned that the break through time of the tracer to the outside atmosphere was as low as 15 minutes. The BATS measurements also showed that concentration build-up at the (less dangerous) turbine end was about 1000 times faster than at the exciter end.

A hand-held halogen leak detector was used to pinpoint leaks in the upper half of the generator that had been opened and was accessible for examinations. With this instrument 2 leaks were identified on bar \#6. Additional leaks were found on bars $\# 8$ and $\# 2$. A few more but very small leaks were found on some bars on the exciter end.

Leak rate quantification focussed on the major leaks at the turbine end. Leaks on bars \#8, \#6 and \#2 were "sniffed" with the DTA (Dual Trap Analyzer) but the leak rates were so low $(0.003 \mathrm{ml} / \mathrm{min}$ at $15 \mathrm{psi})$ that it had to be concluded that other leaks must have existed to account for the approximately $5 \mathrm{ml} / \mathrm{min}$ total leak rate. Most probably these leaks were located in the lower half of the generator that was not accessible during this outage.

\section{Recommendations}

Most leaks become apparent during the maintenance cycle when the hydrogen pressure is released and the stator bar windings are still under water pressure of 30 to $40 \mathrm{psi}$. The hydrogen is being purged by introducing the heavier $\mathrm{CO}_{2}$ into the generator shell and the $\mathrm{CO}_{2}$ is then eliminated by injecting air. Since this operation is performed under atmospheric pressure and lasts only two to three hours it is suggested to decrease the water pressure in the windings $\mathrm{b}$ e f o r e hydrogen purging. To safeguard against possible contamination with $\mathrm{CO}_{2}$ the water in the windings could be replaced with newly treated water. 
A second recommendation pertains to the manufacturer's guide line allowing for $50 \mathrm{ml} / \mathrm{min}\left(2-3 \mathrm{ft}^{3} /\right.$ day) of in-leakage. This threshold value is observed by measuring the vent flow rate from the cooling water tank. By contrast, leak rates as "low" as $0.1 \mathrm{ml} / \mathrm{min}$ of individual bars had caused hipot failure (see chapter 3.1 "Testing of 3 Individual Bars). The measured leak rate for the stator windings proper was about $5 \mathrm{ml} / \mathrm{min}$, one third of the recommended value.

It is therefore suggested that a procedure and specification be developed accounting for leakage from the stator bar windings proper (excluding connections and pump seals). During downtime, testing of the stator bar assembly proper could be accomplished by tagging of the bars and sampling of the closed generator with the DTA. Sampling of the opened generator could be performed with CATS tubes as outlined in this paper. The magnitude and location of possible leaks could be determined and their severity could be gauged against a reliable standard. Together with the hi-pot test such testing would greatly aid in the decision of when to replace leaking bars.

\section{Conclusions}

A detailed leak search protocol was developed both for entire generators and for leaking stator bars removed from the generator. Pressure decay and the tracer "double source" method were used to quantify and corroborate the overall leak rate.

For bars tested separately in the laboratory leak locating was achieved by enclosing the bar with a 1 foot plastic enclosure and by taking air samples from the enclosure with the Dual Trap Analyzer. This was repeated for subsequent sections. The section with the presumed leak was then submerged in a water bath which led to the final pinpointing of the actual leak. The procedure was applied to bars with and without insulation.

Most leaks on the bare copper occurred within a few inches from the water box. Bars \#31 and \#53 removed from unit 1 and 2, respectively, of ConEd's Ravenswood power plant had comparable leak rates, namely 0.1 $\mathrm{ml} / \mathrm{min}$, normalized to an assumed operating pressure differential of $15 \mathrm{psi}$. The travel distance of water under the insulation is usually several feet long, from the water box to the core (straight) section of the bar.

In-situ testing at Union Electric's Labadie power plant proved that attaching CATS sampling tubes to each third bar not only enabled overall leak rate determination but also helped in locating areas of increased tracer 
concentration. The approach revealed a normalized leak rate of $5 \mathrm{ml} / \mathrm{min}$ $\left(0.25 \mathrm{ft}^{3} /\right.$ day $)$ which was $1 / 3$ of the leakage obtained by pressure decay and $1 / 10$ of the manufacturer's recommendatic." which allows for $50 \mathrm{ml} / \mathrm{min}(2.5$ $\mathrm{ft}^{3} /$ day) of in-leakage.

In-situ tests also showed that tracer gas break-through from the windings to the generator shell was less than 15 minutes. The end with the higher leak rate, in this case the turbine end, could be determined and quantified accurately. In-situ tests were not as complete as desired because only the upper half of the generator was accessible.

TTC suggests that the hydrogen purging procedure be revised and that a new in-leakage specification be developed. The new guide line should apply particularly or leakage from the stator bar windings but not include the connections and pump seals. During the maintenance cycle testing of the stator bar assembly proper by applying tracer technology principles should become a routine part of the overhaul procedure.

\section{References}

Loss, W. M., Dietz, R. N., and Senum, G. I. Detection of leaks in a watercooled generator stator bar using perfluorocarbon tracers. Informal Report 43654; Brookhaven National Laboratory, Upton NY, 1989.

Loss, W. M., and Dietz, R. N. Test report: generator stator bar leak quantification and pinpointing. Informal Report 44436; Brookhaven National Laboratory, Upton NY, 1990.

D'Ottavio T. W., Goodrich R. W., and Dietz R. N. Perfluorocarbon measurement using an automated Dual-Trap Analyzer. Environ. Sci. Technol. 20, 100-104 (1986). 


\section{APPENDIX}

\section{APPENDIX A1: Detailed Leak Search Protocol}

\section{Failed Bar Testing}

The testing of single bars that had failed the hi-pot test and had been removed from the generator takes place in two phases. The goal of the first phase is the detection of leaks on the surface of the insulation (the outer layer of asbestos is removed from the bars). During this phase the bar with either the fiberglass or mica insulation still in place is subjected to a series of four tests:

1. Pneumatic pressure decay tests to determine the total leak rate.

2. "Double source" tracer tests to corroborate decay test.

3. Leak locating using tracer and bar enclosure.

4. Leak pinpointing and leak verification in water bath.

During the second phase the leaking part of the stator bar, stripped of all insulation, is submerged in a water bath to locate the actual points of egress on the copper. Hence, phase 2 consisted of only 1 step:

5. Leak pinpointing in water bath

In the following, these steps will be explained in more detail. The pertinent theoretical foundation for the various techniques can be found in Appendix A2 (Theoretical Considerations).

\subsection{Pneumatic pressure decay tests:}

In order to successfully accomplish a pressure decay test on a single bar certain prerequisites have to be met. These are enumerated in the following:

\subsubsection{Assembly of experimental set-up}

The experimental set-up was depicted in Figure 1 and consists 2 of three parts: 
the inlet section,

the stator bar proper, and

an outlet section.

The inlet section includes the gas cylinder with helium for pressure decay which is later replaced with nitrogen containing the tracer. A regulator,

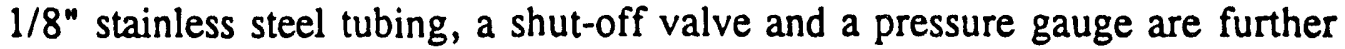
parts of the inlet section. The outlet section is comprised of a shut-off valve, a by-pass to a 1 liter cylinder, an additional pressure gauge and a vacuum pump, all connected by $1 / 8$ " stainless steel tubing.

\subsubsection{Check leak tightness of connecting tubes}

The first step of the leak search protocol is the detection and elimination of possible leaks in the inlet and outlet connecting tubes. Inlet and outlet tubes are directly joined to each other (without the stator bar in between) and then submerged in a water bath. Only when absolute leak tightness of the connecting tubes is assured will the bar be inserted between the inlet and outlet sections.

\subsubsection{Purging}

Purging is an essential stage in the detection procedure because water in capillary cracks virtually plugs the escape route for the pressurized gas. Purging is accomplished by repeated pressurization and sudden depressurization of the bar. To this purpose the bar is filled with helium gas at 200 psi and the outlet valve is opened allowing the leaving gas stream to carry water droplets to the surrounding atmosphere. After repeating the procedure 5 times the bar is evacuated for 24 hours to further enhance the evaporation of water. Helium purging is then repeated 5 more times.

\subsubsection{Check leak tightness of adapters and portion of bar adjacent to water box}

Special adapters are fabricated to connect the stainless steel tubing of the inlet and outlet sections to the particular $11 / 8-16 \mathrm{UN}-2 \mathrm{~B}$ threaded opening of the stator bar. The leak tightness of these adapters is confirmed by submerging the end portion of the stator bar in a water bath. This procedure also achieves a second goal, namely the inspection for leak tightness of the end portion of the bar (up to about 1 foot away from the water box). It is assumed that most of the leaks occur in this area so that early discovery of leakage points close to the water box is essential for a fast testing progress. 


\subsubsection{Determination of volume of bar:}

As will be seen in the next paragraph the knowledge of the internal volume of the bar is necessary for exact leak rate determination. The volume of the bar is established according to a well known pressure/volume correlation for gases which is delineated in Appendix A2.

\subsubsection{Pneumatic Pressure decay test}

After attaining all the preparatory steps the bars can finally be pressurized with helium and the pressure decay is observed over time. Pneumatic leak rate determination is based on the principle that a pressure loss of $1 \mathrm{~atm}$ (or $14.7 \mathrm{psi}$ ) equals the system volume - which has to be known provided constant temperature is maintained during the observation period. This principle is explained in more detail in Appendix A2. The leak rates found in this way are based on the prevailing average system pressure and are in direct relationship to that pressure (increased system pressure induces higher leak rates and vice versa).

\subsection{Tracer Double Source Test for Total Leak Rate Quantification}

The total leak rate found by pressure decay is corroborated with the "double source" method using perfluorocarbon tracers. The bars are pressurized to 200 psi with nitrogen containing the first tracer, namely PMCP (perfluoro-methylcyclopentane). A second tracer source, PMCH (perfluoromethylcyclohexane), enclosed in a small cylindrical (cigarette shaped) container with a known emission rate is also deployed in the room.

Afier a night, when steady state concentrations in the room is reached, the concentrations of the two tracers in the room are measured by taking readings with the Dual Trap Analyzer (DTA, see Appendix A3 for description of this instrument).

The leaking PMCP from the bar and the PMCH from the single source create two particular tracer signatures in the room and, hence, a concentration ratio, $\mathrm{C}_{\mathrm{PMCH}} / \mathrm{C}_{\mathrm{PMCP}}$. That concentration ratio together with the known $\mathrm{PMCH}$ source rate of $10^{-9}$ liters $/ \mathrm{min}$ allow calculation of the PMCP leak rate and the associated nitrogen leak rate (see Appendix A2 for mathematical explanation of this principle). 


\subsection{Leak Locating using Tracer and Bar Enclosure}

The bar is enclosed in a plastic bag of approximately 1 foot length and the bag is moved successively from one end of the bar to the other. At each stop along the way air samples are taken from the bag with the DTA. Analyzing section after section of 1 foot length for PFT content reveals the approximate location of leak(s).

\subsection{Leak Pinpointing and Verification of Leak Rate in Water Bath}

The last step of phase 1 (testing with the insulation) is the immersion of the leaking section of the bar in a water bath. The rising bubbles give an indication of the exact leak origin if the leak originated on the outside (the visible surface) of the outer set of strands. For leaks on inner strands actual leak pinpointing cannot be accomplished because the strands are still tied together by the fiberglass insulation and the exact point of egress can not be determined by visual observation. For these cases, only an approximate leak location on the insulation is estimated.

The bubbles rising through the water bath are captured with an inverted calibrated glass cylinder initially filled with water. The bubbles surface to the top of the cylinder and replace the water. The rate of this replacement is identical to the leak rate. Results of the inverted cylinder method are compared with the earlier pressure decay and "double source" leak rates.

\subsection{Leak Pinpointing on Stripped Bar in Water Bath:}

After having found the leaks on the surface of the insulation the leaking section of the bar is cut off (usually 1 foot downstream from the water box) and sent back to ConEd for removal of the insulation. Upon return to Brookhaven, the open - sawed off - end of the stripped bar is sealed with a special epoxy polymer. The bar is again pressurized and submerged in a water bath to determine the exact leak location on the surface of the copper. Because the strands are not connected with fiberglass anymore they can be separated to inspect and pinpoint leaks on inner strands as well.

\section{In-Situ Testing}

The winding assembly within a generator is tagged with carrier gas (usually nitrogen) containing one tracer (for instance PMCP) and a series of experimenis is conducted in two phases. 
During the first phase the generator shell is enclosed in plastic sheets and the leaking tracer is allowed to build up to a steady state concentration within the enclosure. Phase 1 encompassed the following tests:

1. Pneumatic pressure decay tests to determine the total leak rate.

2. "Double source" tracer tests to corroborate decay test.

3. Approximate leak locating using tracer and CATS tubes.

4. Determination of concentration build-up versus time.

Phase two consists of leak pinpointing and quantification of the individual leak rates. During this phase the plastic sheets are removed from the generator shell. Two steps are performed:

5. Leak pinpointing with halogen leak detector or COPS (see Appendix A3).

6. Quantification of individual leak rates with DTA.

\subsection{Pressure Decay Test}

Purging and pressure decay tests for whole generaturs is conducted by plant personnel as this is a routine procedure during shut down and overhaul.

\subsection{Double Source Test for Total Leak Rate Quantification:}

Evaluation of the total leak rate is possible by taking advantage of the same "double source" principle that was explained for single bars. The second source necessary for this experiment is provided by installing a cylinder with a second tracer (for instance PMCH) within the generator enclosure. That cylinder releases the the tracer with a known flow rate.

The concentration ratio of the two tracers (tracer 1 from the bars and tracer 2 from the cylinder) allows the calculation of the leak rate. The two concentrations are found by "sniffing" with the DTA. In addition, CATS tubes are deployed on every third bar and analysis of these samplers, which are kept in the enclosure for about one day, allows quite accurate determination of the average concentration within the generator shell (see Appendix A3 for description of CATS tubes). 
Because the concentration ratio is measured within the enclosed generator shell leaks outside the enclosure are not part of the calculated leak rate. Thus, the "double source" method is more accurate than the pressure decay approach, which includes leaks in the connections and fittings leading to and from the generator.

\subsection{Approximate Leak Locating:}

This task entails the analysis of CATS tubes that are deployed on every third bar. High concentrations in certair. areas enables faster pinpointing during the next phase.

\subsection{Concentration Build-up versus Time:}

This task is achieved with the help of the BATS programmable sampler (see Appendix A3 for description). With this instrument it is possible to find the break-through time of the tracer from the stator windings into the generator enclosure. That break-through time is crucial because of the limited overall test time available to the TTC team on a field trip.

Tle BATS measurements during concentration build-up also give a clear indication at which of the two opposite ends of the generator the larger leaks occurred since faster build-up indicates a larger leak. This information is important for an assessment of the relative severity of leaks.

\subsection{Leak Pinpointing}

Leak pinpointing can be achieved with a halogen leak detector or with the so-called COPS (Continuously Operating PFT Sniffer). Swift pinpointing is possible with this instrument because areas of high concentration are already identified during "Leak Locating" with the CATS measurements.

\subsection{Quantification of Individual Leak Rates}

Individual leak rates are found by sampling air at "hot spots" with the DTA. A 4 inch diameter funnel is attached to the Dual Trap Analyzer inlet hose. Because the DTA inlet flow rate is 0.250 liters/minute it is assumed that all the escaping tracer from a leak is captured. Dividing the tracer volume by the sampling time yields the leak rate. 


\section{APPENDIX A2: Theoretical Considerations}

\section{Volume of Bar}

If gas from a system with unknown volume but known pressure is allowed to flow into a second system with known volume and known pressure, the reduced pressure of the combined total system permits the calculation of the unknown volume of the first system. This can be expressed in equation form as

$$
P_{\text {stat }} * V_{\text {stat }}+P_{\text {cyl }} * V_{\text {cyl }}=P_{\text {tot }} * V_{\text {tot }}
$$

where

$$
\begin{aligned}
& P_{\text {stat }}=\text { Pressure of the stator bar } \\
& V_{\text {stat }}=\text { Volume of the stator bar } \\
& P_{\text {cyl }}=\text { Pressure of the } 1 \text { liter cylinder (initially } 1 \mathrm{~atm} \text { ) } \\
& V_{\text {cyl }}=\text { Volume of the } 1 \text { liter cylinder } \\
& P_{t a x}=\text { Pressure of the total stator-bar-plus-cylinder assembly } \\
& V_{t a d}=\text { Volume of the total assembly }=V_{\text {stat }}+V_{c y l}
\end{aligned}
$$

Following this rationale the bar assembly is pressurized with nitrogen to 200 psi and a 1 liter cylinder - functioning as system 2 - is attached. The 1 liter cylinder is left at atmospheric pressure. After opening the connecting valve between the two systems the combined (lower) pressure of the total system (namely bar plus 1 liter cylinder) is used to calculate the volume of the first system, e. g. the bar itself.

\section{Pressure Decay}

Pneumatic leak rate determination is based on the principle that a pressure loss of $1 \mathrm{~atm}$ (or $14.7 \mathrm{psi}$ ) equals the system volume provided constant temperature is maintained during the observation period. This is most obvious if a system was filled with air at atmospheric pressure, and the system is evacuated (pressure loss of $1 \mathrm{~atm}$ ). Then, clearly, the air leaving has to be equal the system volume. This principle can be extrapolated to other pressures. For instance, the total leak from a bar having an internal volume of 2 liters and exhibiting a pressure loss of $1 / 2$ atm would be: 2 liters $* 1 / 2=1$ liter total leak volume. If the pressure drop was observed over a period of 20 
hours the leak rate would be: 1 liter $/ 20$ hours = approximately $1 \mathrm{ml} / \mathrm{min}$ (at the average system pressure). This can be expressed in equation form as

$$
\frac{V}{P_{a t m}}=\frac{\dot{V}_{\text {leak }} * \Delta t}{\Delta p}
$$

where

$$
\begin{aligned}
& \mathrm{V}=\text { volume of Bar } \\
& \mathrm{P}_{\mathrm{atm}}=\text { atmospheric pressure }(14.7 \mathrm{psi}) \\
& \dot{V}_{\text {kat }}=\text { leak rate } \\
& \Delta t=\text { time of experiment } \\
& \Delta p=\text { pressure drop }
\end{aligned}
$$

The leak rates found in this way are based on the prevailing average system pressure and are in direct relationship to that pressure (increased system pressure induces higher leak rates and vice versa).

In addition, the pressure in a system and hence the leak rate is dependent on the temperature during the observation period. In other words, the pressure change has two components, one induced by the temperature change and the other caused by actual leaks.

To eliminate the temperature induced pressure drop the universal gas law is invoked for the start (time 1) and end (time 2) of the experiment

$$
\begin{aligned}
& P_{1} * V=n * R * T_{1} \\
& P_{2} * V=n * R * T_{2}
\end{aligned}
$$

or, by dividing Equation (3) by Equation (4)

$$
\frac{P_{1}}{\left(T_{1} / T_{2}\right)}=P_{2, \text { calc }}
$$

where

$\mathrm{n} \quad=$ number of moles

$\mathbf{R}=$ universal gas constant

$\mathrm{P}_{1}, \mathrm{P}_{2}=$ pressures at time 1 and 2 (start and end of experiment)

$\mathrm{T}_{1}, \mathrm{~T}_{2}=$ temperatures at time and 1 and 2 
With the appropriate temperatures inserted into the above equation, the temperature induced, calculated pressure $p_{2, \text { calc }}$ can be found. The difference between $p_{2, \text { calc }}$ and the observed pressure, $p_{2, \text { obs }}$ is the pressure drop, $\Delta p$, due to leaks. This is the value that enters Equation (2).

\section{Double Source Method}

Stator bars are tagged with one tracer (e.g. PMCP) and a second tracer source (e.g. PMCH) with a known emission rate is deployed in a test room.

When steady state concentrations have been reached in the test room, it follows from conservation of mass principles that the magnitude of these concentrations is proportional to their source rate, that is

$$
\frac{C_{1}}{\dot{v}_{1}}=\frac{C_{2}}{\dot{v}_{2}}
$$

where

$$
\begin{gathered}
\dot{v}_{1}=\text { Source rate of first tracer (for instance PMCP) emanating } \\
\text { from stator bar leak } \\
\dot{v}_{2}=\text { Source rate of second tracer } \\
C_{1}=\text { Concentration of first tracer (from stator bar) in room } \\
C_{2}=\text { Concentration of second tracer (from separate source) in room }
\end{gathered}
$$

Hence, the emission rate of the first tracer from the stator bar $\left(\dot{v}_{1}\right)$ can be calculated if the concentrations $C_{1}$ and $C_{2}$ have been determined (for instance by DTA measurements) and if the source rate of the second source $\left(\dot{v}_{2}\right)$ is known.

The leak raie of the carrier gas (e.g. nitrogen) from the stator bar can now be calculated according to

$$
\dot{V}_{\text {leak }}=\frac{\dot{V}_{1}}{C_{s}}
$$

where

$\dot{v}_{\text {leat }}=$ Leak rate of carrier gas

$\dot{v}_{1} \quad=$ Source rate of tracer \#1 obtained from Equ (6) 
$\mathrm{C}_{\mathbf{3}}=$ the concentration of the first tracer within the leaking carrier gas

Equation (7) is derived from the basic relationship which states that the tracer volume is equal to the carrier gas volume times the tracer concentration, C.

\section{APPENDIX A3: PFT Instruments}

\section{The Dual Trap Analyzer}

In the late 1970s, Lovelock, under a contract to the National Oceanic and Atmospheric Administration, built a prototype two-trap instrument that was subsequently modified at BNL. The unit consisted of two adsorbent traps, packed with a charcoal-like adsorbent and an in situ gas chromatograph (GC) equipped with an electron capture detector (ECD).

While one trap was sampling at $1 \mathrm{~L} / \mathrm{min}$ for $5 \mathrm{~min}$, the other was heated to recover and analyze the collected PFTs. Once heated into the GC, the tracers were separated in a charcoal-like packed column (having different adsorption characteristics, different PFTs elute at different times) before being detected in the ECD. Since the traps reversed position every $5 \mathrm{~min}$, no tracer was lost.

A new version of this real-time analyzer was built in 1983 for atmospheric tracer experiments. Improvements allowed the separation of 4 to 5 PFTs in a 4-min chromatogram of a 4-min air sample collected at the rate of $1 \mathrm{~L} / \mathrm{min}$. The unit was able to see down to the ambient levels of PMCP and $\mathrm{PMCH}$, indicative of the limit of detection of about $10 \mathrm{fL}$ (D'Ottavio et al., 1986), i.e., $10 \times 10^{-15}$ liters of tracer.

\section{Programmable Sampler (BATS)}

These samplers were developed at Brookhaven by Dietz. The units measure just $14 \times 10 \times 8$ inches and weigh $7 \mathrm{~kg}$. They contain 23 sampling tubes, each containing $150 \mathrm{mg}$ of a charcoal-like material (Ambersorb) which can retain all the PFTs in more than 30 liters of air. The air is pumped sequentially through one tube after another. The contact time as well as the flow rate can be pre-programmed by an internal computer.

Batteries provide power for up to one month of unattended operation of all the automatic and recording features. In the laboratory, sample recovery is 
accomplished by direct ohmic heating of the adsorption tubes to $400^{\circ} \mathrm{C}$, with the PFTs being purged from the BATS tube through an automated ECD-GC system, analyzing all 23 tube in about 3 hours.

\section{Capillary Adsorption Tube Samplers}

The passive samplers are made from $6 \mathrm{~mm}$ OD by $4 \mathrm{~mm}$ ID glass tubing exactly 2.5 inches long. They contain $64 \mathrm{mg}$ of Ambersorb and - in their non-sampling state - are closed off with small rubber caps. Sampling occurs by the process of Fickian diffusion when one cap is removed. From empirically derived diffusion coefficients of PFTs in air, it was determined that the CATS sampled at a rate equivalent to about $200 \mathrm{ml}$. CATS like BATS tubes have to be desorbed for GC analysis.

\section{Continuously Operating PFT Samplers (COPS)}

This instrument continuously responds to electron capturing tracers by combusting the oxygen with hydrogen over a catalyst bed. Its detection capability is limited to about $30 \mathrm{pL} / \mathrm{L}$. Table Al provides an overview of the current sampling and analysis methodologies.

\section{APPENDIX A4: PFT Technology: Current and Proposed Utility Applications}

Tne following tables give some insight into the current state of the PFT technology and explain future possible applications.

Tables A2 and A3 introduce perfluorocarbon tracers. Table A3 enumerates the fluids to which tracers can be added in order to detect their movement or to find losses from these fluids causer by various kinds of leakage.

Table A4 lists the units for reporting tracer concentrations, since a variety of these may have been mentioned in the course of this paper. Convention would have us use $\mathrm{pL} / \mathrm{L}$ and $\mathrm{fL} / \mathrm{L}$.

Table A5 depicts the naturally occurring compounds whose concentrations exceed those of the PFTs and which are detectable in the electron capture detector (ECD) used to measure the PFTs. Included are $\mathrm{O}_{2}$, nitrogen oxides, chlorofluorocarbons (freons), $\mathrm{SF}_{6}$, and others, each of which could interfere with the early eluting PFTs. A catalyst bed operating at about $200^{\circ} \mathrm{C}$ is 
needed to destroy many of these interfering compounds so that the surviving PFTs can be detected.

Table A6 lists the current and future PFT applications and is self explanatory. 
PERFLUOROCARBON TRACER TECHNOLOGY: SAMPLING AND ANALYSIS METHODOLOGIES

- Sampling methodologies

- Passive samplers (CATS), 0.2 L (air)/day

- Programmable samplers (BATS), variable sampling rates

- Real-time sampling and analysis (DTA) - $30 \mathrm{fL}$

- Analyses

- Real-time continuous (COPS) - $25 \mathrm{pL} / \mathrm{L}$

$$
\frac{\left(25 \times 10^{-12} \mathrm{~L}(\mathrm{PFT})\right)}{\mathrm{L}(\mathrm{air})}
$$

- Laboratory determination from collected samples (GC) - $1 \mathrm{fL}\left(1 \times 10^{-15}\right.$ liter PFT)

- Up to eight PFTs in less than 15 minutes from one sample

Table A1 


\section{PERFLUOROCARBON TRACERS}

- A family (currently 7) of organic liquids.

- perfluorinated alkyl cycloalkanes

- non-toxic, inert

- extremely chemically stable, up to $500^{\circ} \mathrm{C}$

- Vapors detectable in femtogram $\left(10^{-15}\right.$ gram) quantities.

- Gas chromatographic-electron capture detection.

Table A2 
WHAT ARE TRACERS?

TRACERS:

- gaseous compounds used to tag and track the course of VARIOUS SUBSTANCES

- UNIQUELY DETECTABLE AT SUB-PART-PER-TRILLIDN CONCENTRATIONS

TAGGED SUBSTANCES OF UTILITY INTEREST:

- alr

- ATMOSPHERIC TRANSPORT AND DISPERSION

- AIR INFILTRATION IN HOMES AND BUILDINGS

- FORCED AIR HEATING SYSTEM INTEGRITY

- gAS

- LEAKAgE IN STORAgE AND PIPE TRANSPORT

- hater

- BOILER AND CONDENSER TUBE LEAKS

- DISTRICT HEATING STEAM DISTRIBUTION SYSTEM LEAKS

- OIL

- LEAKAGE FROM HIGH-PRESSURE OIL-FILLED (HPOF) TRANSMISSION CABLES

Table A3 
Units for atmospheric PFT concentrations

1. Parts-per-trilliton

- ppt

- $x 10-12$

- $p$ p 1012

- nL/m (nanoliters/cubic meter)a

- pL/L (picoliters/liter)a

2. Parts-per-quadrillion

- ppq

- $\times 10^{-15}$

- $\mathrm{pp} 1015$

- $\mathrm{pL} / \mathrm{m}^{3}$

- fL/L (femtoliters/liter)a

anano $\left(10^{-9}\right)$, pico $(10-12)$, femto $(10-15)$

Table A4 
Some components in the atmosphere

\begin{tabular}{|c|c|c|c|c|}
\hline Gas & $\begin{array}{r}\text { Rural Concentr } \\
\text { PP } 10^{12} \\
\end{array}$ & ation, & Formula & $\begin{array}{c}\text { Concentration } \\
\text { Range }\end{array}$ \\
\hline $\begin{array}{l}\text { Nitrogen } \\
\text { Oxygen } \\
\text { Argon }\end{array}$ & $\begin{array}{r}780,900,000 \\
209,500,000 \\
9,300,000\end{array}$ & $\begin{array}{l}000 \\
000 \\
000\end{array}$ & $\begin{array}{l}\mathrm{N}_{2} \\
\mathrm{O}_{2} \\
\mathrm{~A}^{2}\end{array}$ & $\%$ \\
\hline $\begin{array}{l}\text { Carbon dioxide } \\
\text { Methane }\end{array}$ & $\begin{array}{r}335,000 \\
1,480\end{array}$ & $\begin{array}{l}000 \\
000\end{array}$ & $\begin{array}{l}\mathrm{CO}_{2} \\
\mathrm{CH}_{4}\end{array}$ & $\mathrm{ppm}$ \\
\hline $\begin{array}{l}\text { Nitrous oxide } \\
\text { Ozone } \\
\text { Nitrogen oxides }\end{array}$ & $\begin{array}{r}315 \\
35 \\
3,\end{array}$ & $\begin{array}{l}000 \\
000 \\
000\end{array}$ & $\begin{array}{l}\mathrm{N}_{2} \mathrm{O} \\
\mathrm{O}_{3} \\
\mathrm{NO}, \mathrm{NO}_{2}\end{array}$ & $\mathrm{ppb}$ \\
\hline $\begin{array}{l}\text { Methyl chloride } \\
\text { Freon } 12 \\
\text { Freon } 11 \\
\text { Carbon tetrachloride } \\
\text { Chloroform }\end{array}$ & & $\begin{array}{r}630 \\
305 \\
186 \\
135 \\
20\end{array}$ & $\begin{array}{l}\mathrm{CH}_{3} \mathrm{Cl}_{1} \\
\mathrm{CCl}_{2} \mathrm{~F}_{2} \\
\mathrm{CCl}_{3} \mathrm{~F}^{2} \\
\mathrm{CCl}_{4} \\
\mathrm{CHCl}_{3}\end{array}$ & ppt \\
\hline $\begin{array}{l}\text { Sulfur hexafluoride } \\
\text { Bromotrifluoromethane } \\
\text { Perfluorodimethylcycl } \\
\text { Perfluoromethylcycloh } \\
\text { Perfluoromethylcyclop }\end{array}$ & $\begin{array}{l}\text { e (F13B1) } \\
\text { lohexane } \\
\text { hexane } \\
\text { pentane }\end{array}$ PFTs & $\begin{array}{l}0.85 \\
0.75 \\
0.022 \\
0.0045 \\
0.0032\end{array}$ & $\begin{array}{l}S_{F} \\
C_{6} F_{3} \\
C_{8 F_{16}} \\
C_{7 F_{14}} \\
C_{6} F_{12}\end{array}$ & $\mathrm{ppq}$ \\
\hline $\begin{array}{l}\text { Perfluorodimethylcycl } \\
\text { Deuterated methane } \\
\text { Deuterated methane } \\
\end{array}$ & lobutane) & $\begin{array}{l}0.00034 \\
0.00030^{\mathrm{a}} \\
0.00001^{\mathrm{a}}\end{array}$ & $\begin{array}{l}\mathrm{C}_{6} \mathrm{~F}_{12} \\
\mathrm{CD}_{4} \\
13 \mathrm{CD}_{4}\end{array}$ & $s u b-p p q$ \\
\hline
\end{tabular}

acurrent limits of detection; actual background estimated at $<0.000001$ pp $10^{12}$. 
UTILITY-RELATED APPLICATIONS

\section{CURRENT RESEARCH STUDIES}

1. HPOF CABLE OIL LEAK DETECTION

- 25 Gal. TAGged aT 0.03 WT $\%$

- lear located to 1/2 block by aerial sampling

- PINPOINTED to 5 fEet by baRHoling

2. GENERATOR STATOR BAR LEAK

- REMOVED FROM GENERATOR (WATER POUND ON SURPACE)

- TOTAL LEAK QUANTIFICATION AND LOCALIZATION

- Leak pinpointino to less than $1 \times 10^{-17} \mathrm{~L} / \mathrm{S}$ Of $\mathrm{H}_{2}$

3. UNDERGROUND STORAGE TANK (UST) MONITORING

- LEAK TIGHTNESS VERIPICATION

- LEAK pinpointina

Table A6 


\section{UTILITY RELATED APPLICATIONS}

\section{PROPOSED RESEARCH STUDIES}

1. UNDERGROUND STORAGE TANK (UST) MONITORING

- LEAK TIGHTNESS VERIPICATION

- LEAK PINPOINTING

2. VENTILATION EPPECTIVENESS

- EQUIPMENT WASTE HEAT RECOVERY

- SURROGATE FOR ASBESTOS DURING REMOVAL

3. FLUID FLOW MONITORING

- COOLING WATER FOR BETTER HEAT BALANCES

- PPT EMULSION FOR TUBE FOULING QUANTIFICATION

- ON-LINE STEAM QUALITY: PFTS OR CONDENSATION COIL

4. LEAK DETECTION

- GENERATOR H2-COOLANT LEAKAGE

- ePFEctiveness op h2 AND aIR coOling

- condenser aIR-TO-VAcUum monitoring

- $\mathrm{H}_{2}$ STORAGE TANK AND PIPING LEAK LOCATING

- UNDERGROUND FUEL OIL AND GAS PIPING FUgITIVE EMISSIONS

- COMMISSIONING TESTS FOR GAS LINES

- SUBMARINE HPOP CABLES

- MEg EPFECTIVENESS

- GAS-PILLED ELECTRIC CABLE LEAK LOCATING

- SPG-INSUlated ELECTRICAL EQUIPMENT LEARS

- consumer piping leaks (Water aNd gas)

- COMMISSIONING

- MONITORING

Table A6 (con't) 
UTILITY-RELATED APPLICATIONS

PROPOSED RESEARCH STUDIES (CONTINUED)

5. TRIBOLOGY (WEAR)

- AgING OP COMPONENTS IN INACCESSIBLE AREAS

- ENCAPSUlated PFT-MICROSPHERES

- IMPREGNATED ELASTOMERIC SEALS

6. NUCLEAR FACILITIES

- CONTAINMENT INTEGRITY

- COMMISSIONING

- MONITORING

- EQUIPMENT LEAKAGE

- ON-LINE MONITORING

7. LAND-FILL MONITORING

- gAS MIGRATION

- aQUifer contamination

४. VEGETATION MANAGEMENT

- HERBICIDE MIGRATION TO AQUIFER

9. ATMOSPHERIC TRANSPORT

- MODEL VALIDATION FOR SITE BOUNDARY IMPACTS

- "REAL-TIME" TRANSPORT IMPACTS

- "LONG-TERM" (DAILY, WEEKLY, ETC.) STUDIES

Table A6 (con't) 
DATE FILMED $2 / 07 / 92$ 
